\title{
KNOWLEDGE ABOUT PREGNANCY DANGER SIGNS AMONG MOTHERS ATTENDING ANTENATAL CARE IN JUGAL HOSPITAL, HARARI REGIONAL STATE, ETHIOPIA, 2019
}

\author{
Arif Hussen* \\ Harar Health Science College, Department of Pediatrics Nursing, East Ethiopia
}

Received: 10 September 2019| Accepted: 20 September 2019

Correspondence:

Arif Hussen, MSC

Harar Health Science College, Department of Pediatrics Nursing, East Ethiopia

Telephone 025-666-0255, p.o.box\# 806, Harar, Ethiopia

Email address: arifhussen.ah@gmail.com

Copyright: (C) the author(s), YCAB publisher and Public Health of Indonesia. This is an open-access article distributed under the terms of the Creative Commons Attribution Non-Commercial License, which permits unrestricted non-commercial use, distribution, and reproduction in any medium, provided the original work is properly cited.

\begin{abstract}
Background: Every pregnant woman faces the risk of sudden, unpredictable complication that could end in death or injury to mother or infant. Each year, approximately 287,000 women die from complications related to pregnancy and childbirth in developing countries. Maternal mortality ratio (MMR) in developing regions is 15 times (240/100,000 live births) higher than in developed regions $(16 / 100,000$ live births $)$

Objective: The aim of this study was to determine the knowledge about pregnancy danger signs among mothers attending antenatal care in Jugal Hospital, Harari Regional State, Ethiopia.

Methods: Institution based cross-sectional study design was conducted. A systematic random sampling technique was used to select study participants from pregnant mothers attending antenatal care during the time of data collection. Data were collected using a structured questionnaire and it was entered in to EPI Data version 3.1 software program and exported to SPSS version 20 software for analysis.

Results: A total of 316 pregnant women were included in the study with a response rate of $86 \%$. The study indicated that $44.67 \%$ of the respondents had knowledge on danger signs of pregnancy, and there was a significant association with the knowledge on danger signs of pregnancy and the age of the respondent and educational status of the respondent $(P<0.05)$.

Conclusion: The study finding shows that poor awareness about danger signs of pregnancy among antenatal care attendants in Jugal hospital, Harari Regional State. There was a significant association between educational status, the age of the mother and knowledge about pregnancy danger signs among mothers attending antenatal care.
\end{abstract}

Keywords: danger sign, knowledge, antenatal care, Ethiopia, pregnancy

\section{BACKGROUND}

Every pregnant woman faces the risk of sudden, unpredictable complication that could end in death or injury to mother or infant (Central Statistical Agency and ORC Marco, 2016). Danger signs are problems that face the mother during pregnancy, labor and the postpartum period. This includes bleeding from the vagina, no matter how slight, swelling of the face or hands or legs, severe headache, dimness or blurring of vision, severe or continuous pain in the abdomen. In addition, it includes severe or continuous vomiting, chills or fever, pain or burning with urination, sudden escape of fluid from the vagina in the second half of pregnancy, if the baby (fetus) moves less than you are used to, or stops moving and pelvic or abdominal pain (Midhet \& Becker, 2010). 
Each year, approximately 287,000 women die from complications related to pregnancy and childbirth in developing countries. Maternal mortality ratio (MMR) in developing regions is 15 times (240/100,000 live births) higher than in developed regions $(16 / 100,000$ live births) (Requejo, Victora, \& Bryce, 2014).

Sub-Saharan Africa had the highest maternal mortality ratio at 500 maternal deaths per 100,000 live births. Most of the studies have been reported that Ethiopia is one of the six countries that contribute about $50 \%$ of the maternal deaths; the others are India, Nigeria, Pakistan, Afghanistan and the Democratic Republic of Congo (World Health Organization, 2015).

Studies conducted in South West Ethiopia, Arbaminch and Benchmaji indicated that the level of awareness on pregnant women about obstetric danger signs during pregnancy was low (Dile, Taddesse, Gedefaw, \& Asmama, 2015; D. Hailu \& Berhe, 2014). Low awareness of danger signs and symptoms during pregnancy contribute to delays in seeking and receiving skilled care. For that matter, increased awareness is essential for reducing delays in seeking health care and in reaching a health facility.

Despite these all problem, no articles found in the study area showing the severity of the problem that encourage the concerned bodies to take remedial action. The study therefore aims to fill this gap by assessing the current status of knowledge about pregnancy danger signs among mothers attending Antenatal Care (ANC) in Jugal hospital, Harai Regional State, Ethiopia, 2019.

\section{METHODS}

Study setting and study design

The study was conducted at Jugal Hospital, Harar City, which is located $525 \mathrm{~km}$ to East of Addis Ababa. It has a total of 342 staff, which 208 of them are health care professionals and the rest are non-health professionals, administrative staff of the hospital found in
Harar towns. It is the first governmental hospital in Ethiopia established in 1902 GC, named as Misrak Arbegnoch Hospital, and the hospital changed its name to Jugal Hospital. Currently, the hospital is providing ANC with six midwives, two of them are BSc and the rest are diploma nurses. Institutional based quantitative cross-sectional study design was conducted. Data were collected from June $1^{\text {th }}$ $15^{\text {th }}, 2019$.

Sample size determination and sampling procedure

All pregnant women attending ANC were selected if met the inclusion criteria. Systematic random sampling was used. The inclusion criteria were all mothers who gave birth in the hospital and have willing to participate in the study. The following assumptions were made to determine the sample size: The formula to calculate the sample size was $n=(z \alpha / 2)^{2} p(1-$ p) $/ D^{2}$, where $\mathrm{n}=$ number of the study subjects, $Z=$ the standardized normal distribution curve value for the $95 \%$ confidence interval (1.96), $P=$ the level of knowledge on obstetric danger signs during pregnancy, it was $31.9 \%$ in the study done in Balegoba (7) BBogale, 2015 \#162\}(Bogale \& Markos, 2015), $d=$ the desired precision of the estimate (the margin of error between the sample and population, 5\%) = $(1.96)^{2} \mathrm{x} 0.319(1-0.319) /(0.05)^{2}=333+33$ $=366=$ the total sample size after computing for $10 \%$ non-response rate was 366 .

Data collection, quality and analysis

Data were collected using a structured questionnaire. The data collectors were four BSc. midwives. The questionnaire was gathered and checked for completeness. For data processing and analysis, SPSS version 20 was used. Data were checked for completeness and consistency. Coded data were entered into computer programs after the required cleaning was done. Univariate, bivariate and multivariate analysis were carried out. Odds ratio (OR) with confidence intervals and $P$ values were calculated the output of the analysis were given, and odds ratio with their respective confidence intervals. $P$-value of 0.05 was taken as level of significance. 
Ethical considerations

Ethical clearance was obtained from Harar Health Science College research ethical committee before the staring of the field work. An official letter of co-operation was written to Jugal Hospital. Consent was obtained from administrative body of the hospital and the participants. Confidentiality of the data has been kept throughout the study.

\section{RESULT}

Socio-Demographic Characteristics of Participants

Among a total of 366 sampled participants, 316 mothers were participated making response rate of $86 \% .38 .61 \%$ of the participants aged $26-29$ years. Majority of participants $(94.94 \%)$ were married, and $60.13 \%$ of them were housewives. Majority had illiterate level of educational status (34.18\%) (Table 1).

Table 1 Distribution of Socio-Demographic Characteristics of Respondents

\begin{tabular}{|c|c|c|c|}
\hline Variable & & Frequency & Percent (\%) \\
\hline \multirow[t]{6}{*}{ Age } & $15-19$ & 10 & 3.16 \\
\hline & $21-25$ & 85 & 26.90 \\
\hline & $26-29$ & 122 & 38.61 \\
\hline & $30-34$ & 55 & 17.41 \\
\hline & $35-39$ & 34 & 10.76 \\
\hline & $\geq 40$ & 10 & 3.16 \\
\hline \multirow[t]{2}{*}{ Marital status } & Single & 16 & 5.06 \\
\hline & Married & 300 & 94.94 \\
\hline \multirow[t]{3}{*}{ Religion } & Orthodox & 75 & 23.73 \\
\hline & Muslim & 205 & 64.87 \\
\hline & Protestant & 36 & 11.39 \\
\hline \multirow[t]{5}{*}{ Ethnicity } & Oromo & 196 & 62.03 \\
\hline & Amhara & 95 & 30.06 \\
\hline & Tigre & 5 & 1.58 \\
\hline & Harari & 15 & 4.74 \\
\hline & Ethio- Somale & 5 & 1.58 \\
\hline \multirow[t]{3}{*}{ Occupation } & House Wife & 190 & 60.13 \\
\hline & Employee of GO/NGO & 101 & 31.96 \\
\hline & Business & 25 & 7.91 \\
\hline \multirow[t]{5}{*}{ Educational Status } & Illiterate & 108 & 34.18 \\
\hline & Read and Write & 69 & 21.84 \\
\hline & Elementary & 30 & 9.49 \\
\hline & Secondary & 49 & 15.51 \\
\hline & College or University & 60 & 18.99 \\
\hline
\end{tabular}

\section{Obstetric Characteristics of the Respondents}

From the total number of respondents, 133 $(42.09 \%)$ had history of 2 pregnancies and 26 $(8.23 \%)$ mothers were pregnant for more than four times. Regarding the first pregnancy age,
217 (31.33\%) mothers got their first pregnancy at age greater than 20 years. Of the total number respondents, $75(23.73 \%)$ had previous risk of pregnancy. In the case of ANC follow up, only $15(4.7 \%)$ mothers had $\geq 4$ visits (Table 2 ).

Table 2 Obstetric characteristics of the respondents

\begin{tabular}{llcc}
\hline Variables & & Frequency & Percent \\
\hline \multirow{3}{*}{ Gravid } & 1 & 88 & 27.85 \\
& 2 & 133 & 42.09 \\
& $\geq 3$ & 95 & 30.06 \\
\hline \multirow{3}{*}{ Parity } & None & 88 & 27.85 \\
& $1-4$ & 202 & 63.92 \\
Age at $1^{\text {st }}$ pregnancy & $\geq 4$ & 26 & 8.23 \\
& $<20$ & 99 & 68.67 \\
\hline
\end{tabular}




\begin{tabular}{llcc}
\hline Variables & & Frequency & Percent \\
\hline Previous risk of pregnancy & Yes & 75 & 23.73 \\
& No & 241 & 76.27 \\
\hline Number of ANC visit & 1 & 146 & 46.20 \\
& $2-3$ & 155 & 49.05 \\
& $\geq 4$ & 15 & 4.75 \\
\hline
\end{tabular}

\section{Source of Information Regarding Obstetric Danger Signs During Pregnancy}

There were 311 participants $(98.42 \%)$ had heard obstetric danger signs during pregnancy. From those who heard obstetric danger signs majority, $251(80.7 \%)$ of the study participants answered the signs that indicated the pregnant or/and the pregnancy has illness. 175 participants $(56.27 \%)$ had got danger signs information from health personnel followed by media, friends and relatives with 106(34.08\%), $21(6.75 \%)$ and $9(2.89 \%)$ respectively.

\section{Knowledge on Danger Signs During Pregnancy}

Of the 316 respondents, 311 (98.42\%) reported that they had got information about obstetric danger sign during pregnancy. From those who had the information, 246 respondents $(79.10 \%)$ identified severe vaginal bleeding at any time during pregnancy as danger sign, while the least was fever identified only by 56 participants (18.01\%) (Table 3).

Table 3 Knowledge on Danger Signs During Pregnancy Among Participants

\begin{tabular}{clcc}
\hline No & Danger sign pregnancy & Frequency & Percent \\
\hline 1 & Vaginal bleeding & 246 & 79.10 \\
2 & Absent/ decreased fetal movements & 189 & 60.77 \\
3 & Convulsion & 179 & 57.56 \\
4 & Severe vomiting & 178 & 57.33 \\
5 & swelling of the body & 168 & 54.02 \\
6 & foul smelling vagina discharge & 142 & 45.66 \\
7 & blurring of version & 79 & 25.40 \\
8 & Severe abdominal pain & 63 & 20.26 \\
9 & Severe frontal headache & 57 & 18.33 \\
10 & Fever & 56 & 18.01 \\
\hline
\end{tabular}

The study participants who responded correctly considered having awareness about danger signs of pregnancy. Based on this, 138 respondents (44.67\%) have knowledge, and 173 respondents (55.33) do not have knowledge about danger sign of pregnancy.

\section{Factor Affecting Knowledge of Danger Sign During Pregnancy}

In bivariate logistic regression analysis, age, marital status, occupation, educational status, age of the $1^{\text {st }}$ pregnancy, and number of ANC visit were statistically significant associated with knowledge of danger sign during pregnancy. Variables which showed statistically significant associations with knowledge of danger sign during pregnancy in the bi-variate analysis were re-entered into multi-variate logistic regression, to control possible confounders.
After controlling the effect of other predictor variables, the multivariate logistic regression analysis showed statistically significant association between maternal age and knowledge of danger sign during pregnancy, as well as between educational status and knowledge of danger sign during pregnancy with $P$-value $<0.05$.

In this study, the odds of having knowledge of danger sign during pregnancy was 7.21 times higher among literate group than illiterate group (AOR $=7.21 ; \quad 95 \% \quad$ CI $=1.17-27.90$ ). Furthermore, in this study, the odds of having knowledge of danger sign during pregnancy was 1.43 times higher among age greater than or equal to 26 years of age group than age less than 26 years of age group $(\mathrm{AOR}=1.43 ; 95 \%$ $\mathrm{CI}=1.05-1.89$ ). 


\section{DISCUSSION}

This research revealed that $79.10 \%$ of respondents knew vaginal bleeding, $60.77 \%$ reduced fetal movement, and $54.02 \%$ swollen hand and face as danger sign of pregnancy. This finding is higher than study done at rural Tanzania which revealed $45.9 \%$ vagina bleeding, $1.2 \%$ reduced fetal movement, and $10.7 \%$ swollen hand and face (Mushi, Mpembeni, \& Jahn, 2007). This difference might be due to the difference study areas, study design or sample size, the major difference might be this study was institutional at urban, but study done at Tanzania were community based in rural area.

This study finding showed that $44.67 \%$ of the participants had knowledge about danger signs of pregnancy, which is higher than studies done in Alexandria, Egypt 26\% (Rashad \& Essa, 2010), Jordan 15.2\% (Okour, Alkhateeb, \& Amarin, 2012), Uganda 20\% (Mbalinda et al., 2014), South Africa 16\% (Coleman, 2014), Tanzania $14.8 \%$ (Urassa, Pembe, \& Mganga, 2012), Debra Birhan town 38.6\% (Solomon, Amanta, Chirkose, \& Badi, 2015), AletaWondo 30.4\% (M. Hailu, Gebremariam, \& Alemseged, 2010), Dar-es-salaam, Tanzania 31\% (Mwilike, 2013), and Salem, Tamil Nadu 34\% (Mahalingam \& Venkateasan, 2014). In contrary, it was lower than study done in other part of Ethiopia, Tsegedi distric 58.8\% (D. Hailu \& Berhe, 2014), Debark town north west 47\% (Mengesha \& Taye, 2012), East Gojjam Zone 55.1\% (Amenu, Mulaw, Seyoum, \& Bayu, 2016), and Mekelle city Tigray $82.5 \%$ (Abiyot, Kassa, Buruh, \& Kidanu, 2014). The differences might be due to the difference study area, sample size, study setting and might be due variation in socio-economic difference of study participates.

In this study, the educational status of study participants affected the level of awareness, as educational status increase, the level of awareness also increases. This is similar with studies done in Indonesia (Sugiyarto, 2007), Uganda (Kabakyenga, Östergren, Turyakira, \& Pettersson, 2011), Bench maji (Demissie, Dessie, \& Michael, 2015), and Mekele (Abiyot et al., 2014), showed that as educational status increases awareness also increased. The education is believed to be the most powerful influencing factor to increase women's' knowledge about danger signs of pregnancy.

In this study, maternal age was one factor that has been indicated as predictors of awareness of danger signs of pregnancy. When maternal age increases level of awareness of danger sign of pregnancy became good. This finding is consistent with studies done in Tsegedi district (D. Hailu \& Berhe, 2014), Debark town North West Ethiopia 66.8\% (Mengesha \& Taye, 2012), Egypt (Rashad \& Essa, 2010), and Tanzania (Urassa et al., 2012), Dar-es-salaam, Tanzania (Mushi et al., 2007), Arba Minch Ethiopia (Workineh et al., 2014), and Mekelle city Tigray (Demissie et al., 2015), but inconsistent with study done in Southeast Nigeria (Ossai \& Uzochukwu, 2015) that showed younger age groups were aware than elderly. This might be explained as increased awareness among older women may be related to their own experiences of pregnancy and delivery which is an important source of their information, especially those who had complications associated with their pregnancy.

\section{Limitation of the study}

Since it was confined to women visiting governmental health institution, the findings might not be generalized to the women who did not visit health institution.

\section{CONCLUSIONS}

The study finding shows that poor awareness about danger signs of pregnancy among ANC attendants in Jugal hospital, Harari Regional State was identified. There was a significant association between educational status, the age of the mother, and knowledge about pregnancy danger signs among mothers attending ANC in Harari regional state. Based on finding of this study, the following recommendations are forwarded. As women's awareness about danger signs of pregnancy increased in line with the increase of educational status, it is suggested that women must empower to get 
higher educational degree. The health education related to danger signs of pregnancy to minimize pregnancy related complications is also necessary.

Declaration of Conflicting Interest

There is no conflicting of interest.

Acknowledgment

I acknowledge all data collectors as well as all mothers who participate in the study.

\section{REFERENCES}

Abiyot, T., Kassa, M., Buruh, G., \& Kidanu, K. (2014). Awareness of obstetric danger signs and its associated factors among pregnant women in public health institutions, Mekelle City, Tigray, Ethiopia 2014. Journal of Pregnancy Child Health, 2(3), 1-6.

Amenu, G., Mulaw, Z., Seyoum, T., \& Bayu, H. (2016). Knowledge about danger signs of obstetric complications and associated factors among postnatal mothers of Mechekel District Health Centers, East Gojjam Zone, Northwest Ethiopia, 2014. Scientifica, 2016.

Bogale, D., \& Markos, D. (2015). Knowledge of obstetric danger signs among child bearing age women in Goba district, Ethiopia: a cross-sectional study. BMC Pregnancy and Childbirth, 15(1), 77.

Central Statistical Agency and ORC Marco. (2016). Ethiopian demographic and health survey, 2011. Addis Ababa, Ethiopia and Calverton, Maryland, USA: Central Statistical Agency and ORC Marco.

Coleman, A. (2014). The use of ICT tools (mobile phones) to improve awareness of pregnancy danger signs among pregnant women in rural communities of South Africa. Journal of Communication, 5(2), 203-209.

Demissie, E., Dessie, F., \& Michael, F. (2015). kahsay T, Tadele N (2015) Level of awareness on danger signs of pregnancy among pregnant women attending antenatal care in Mizan Aman General Hospital, Southwest, Ethiopia: Institution Based Cross-sectional Study. Journal of Women's Health Care, 4(288), 2167-0420.1000288.

Dile, M., Taddesse, D., Gedefaw, M., \& Asmama, T. (2015). Knowledge of obstetric danger signs and its associated factors in Debaytilatgin District, Ethiopia: a community based cross sectional study. Gynecology Obstetric (Sunnyvale), 5(9), 315

Hailu, D., \& Berhe, H. (2014). Knowledge about obstetric danger signs and associated factors among mothers in Tsegedie District, Tigray Region, Ethiopia 2013: community based crosssectional study. Plos One, 9(2), e83459.

Hailu, M., Gebremariam, A., \& Alemseged, F. (2010). Knowledge about obstetric danger signs among pregnant women in Aleta Wondo District,
Sidama Zone, Southern Ethiopia. Ethiopian Journal of Health Sciences, 20(1).

Kabakyenga, J. K., Östergren, P.-O., Turyakira, E., \& Pettersson, K. O. (2011). Knowledge of obstetric danger signs and birth preparedness practices among women in rural Uganda. Reproductive Health, 8(1), 33.

Mahalingam, G., \& Venkateasan, M. (2014). Mother's knowledge of warning signs of pregnancy, labour and puerperium. International Journal of Medical Science and Public Health, 3(6), 720723.

Mbalinda, S. N., Nakimuli, A., Kakaire, O., Osinde, M. O., Kakande, N., \& Kaye, D. K. (2014). Does knowledge of danger signs of pregnancy predict birth preparedness? A critique of the evidence from women admitted with pregnancy complications. Health Research Policy and Systems, 12(1), 60.

Mengesha, E., \& Taye, H. (2012). The level of awareness on danger signs of pregnancy and associated factors among ANC attendant pregnant women in Debark Town, North West Ethiopia, 2012. Placenta, 1, 6 .

Midhet, F., \& Becker, S. (2010). Impact of communitybased interventions on maternal and neonatal health indicators: Results from a community randomized trial in rural Balochistan, Pakistan. Reproductive Health, 7(1), 30.

Mushi, D. L., Mpembeni, R. M., \& Jahn, A. (2007). Knowledge about safe motherhood and HIV/AIDS among school pupils in a rural area in Tanzania. BMC Pregnancy and Childbirth, $7(1), 5$.

Mwilike, B. (2013). Knowledge of danger signs during pregnancy and subsequent health seeking actions among women in Kinondoni municipality, Tanzania. Makerere University,

Okour, A., Alkhateeb, M., \& Amarin, Z. (2012). Awareness of danger signs and symptoms of pregnancy complication among women in Jordan. International Journal of Gynecology \& Obstetrics, 118(1), 11-14.

Ossai, E., \& Uzochukwu, B. (2015). Knowledge of danger signs of pregnancy among clients of maternal health service in urban and rural primary health centres of Southeast Nigeria. Journal of Community Medicine and Health Education, 5(337), 2161-0711.1000337.

Rashad, W. A., \& Essa, R. M. (2010). Women's awareness of danger signs of obstetrics complications. Journal of American Science, 6(10), 1299-1306.

Requejo, J., Victora, C., \& Bryce, J. (2014). Data resource profile: countdown to 2015: maternal, newborn and child survival. International Journal of Epidemiology, 43(2), 586-596.

Solomon, A. A., Amanta, A., Chirkose, E., \& Badi, M. B. (2015). Knowledge about danger signs of pregnancy and associated factors among pregnant women in Debra Birhan Town, Central Ethiopia. Science Journal of Public Health, 3(2), 269-273. 
Sugiyarto, T. (2007). Knowledge and practice of maternal health care in Indonesia. Jurnal Kependudukan Indonesia, 2(2), 1-17.

Urassa, D. P., Pembe, A. B., \& Mganga, F. (2012). Birth preparedness and complication readiness among women in Mpwapwa district, Tanzania. Tanzania Journal of Health Research, 14(1).

Workineh, Y., Hailu, D., Gultie, T., Degefu, N., Mihrete, M., Shimeles, M., . . . Alemu, M. (2014). Knowledge of obstetric danger signs and its associated factors in Arba Minch town,
Ethiopia. American Journal of Health Research, 2(5), 255-259.

World Health Organization. (2015). Monitoring health inequality: An essential step for achieving health equity: World Health Organization.

Cite this article as: Hussen, A. (2019). Knowledge about pregnancy danger signs among mothers attending antenatal care in Jugal Hospital, Harari Regional State, Ethiopia, 2019. Public Health of Indonesia, 5(3): 73-79. 